\title{
DERECHO DE FAMILIA
}

\section{Bernardita Conley Garrido"}

DE LA REPUDIACIÓN DE FILIACIÓN DETERMINADA POR PARTO

OF REPUDIATION THE MATERNITY DUE TO CHILDBIRTH

Corte de Apelaciones de Antofagasta,

03 DE MARZO DE 2020, ROL N. ${ }^{\circ} 571-2020$

\section{Resumen}

En el presente comentario se analiza el caso de repudio de la maternidad por parto, y la confusión en que incurren el Registro Civil y la Corte de Apelaciones de Antofagasta entre este acto de renuncia de derechos y la institución de la impugnación de maternidad.

Palabras Clave: repudiación; determinación de filiación por parto; renuncia a derechos

\begin{abstract}
This commentary analyzes a case related to a maternity repudiation due to childbirth and the confusion incurred between the Civil Registry (Registro Civil e Identificación) and the Court of Appeals of Antofagasta due to act of right's waiver because of the impugnation of a maternity being as a legal institution.

KEYWORDS: repudiation; determination of filiation due to childbirth; waiver of rights

* Docente de derecho civil, Escuela de Derecho, Facultad de Humanidades, Universidad Mayor, Chile. Magíster en derecho mención derecho civil, Pontificia Universidad Católica de Valparaíso. Dirección postal: Avenida Manuel Montt 367, cuarto piso. Correo electrónico: bernardita. conley@umayor.cl

Recepción: 2021-06-16; aceptación: 2021-10-01.
\end{abstract}




\section{SíNTESIS DEL CASO}

A. B. P. L dedujo un recurso de protección en contra de la oficina del Servicio de Registro Civil e Identificación de Antofagasta, por los hechos que se relatan. Indicó que su registro de nacimiento originario consigna como padres de filiación no matrimonial a C. A. P. B y M. C. L. B. No obstante, alegó que no tuvo relación con ellos y que en sus 19 años de vida fueron sus abuelos maternos sus figuras paternas. Estos últimos incoaron una acción de adopción a su respecto, pero no fue acogida. Por eso, A. B. P. L. suscribió una escritura pública mediante la cual efectuó una repudiación de la filiación materna y paterna, solicitando su subinscripción ante el Servicio. En consecuencia, el Registro Civil procedió a la subinscripción de repudiación paterna, permitiendo así que el abuelo paterno reconociera como hijo al actor, pero rechazó la subinscripción de repudiación materna.

Los motivos que fundaron la resolución del Registro Civil se consignaron por medio del memorándum n. ${ }^{\circ} 13451$, refiriendo que el parto fue acreditado mediante comprobante emitido en el hospital regional de Antofagasta, además de la inscripción requerida por el padre C. A. P. B., y

"teniendo presente que por regla general la maternidad no se determina por reconocimiento de la madre, la citada disposición del artículo 191 que establece el repudio, no es aplicable a la maternidad, por cuanto ésta emana del documento médico que acredita el hecho del parto y no de un acto jurídico realizado expresa y determinadamente por la madre con la finalidad de reconocer a su hijo como tal"1.

El recurrente declaró no haber aceptado el reconocimiento de quienes figuraban en su partida como padres, de forma expresa o tácita, por lo que ya cumplida su mayoría de edad podría repudiar la filiación en atención al artículo 192 del Código Civil. De tal forma, estimó vulnerados el

"derecho a la vida e integridad física y psíquica; la igualdad ante la ley y principio de no discriminación; la igual protección de la ley en el ejercicio de sus derechos y su derecho de propiedad"

y señaló que el Registro Civil confundió “determinación de maternidad” con "reconocimiento".

Este caso nos permite cuestionar si el artículo 192 del Código Civil limita, en los hechos, la repudiación de maternidad. Con este fin, nos referiremos a la determinación y reconocimiento de maternidad en el Código Civil, para luego examinar los fundamentos de la repudiación y, así, ofrecer al lector un análisis

\footnotetext{
${ }^{1}$ Reproducido en cons. $1 .^{\circ}$ de la sentencia A. B. P. L con Servicio de Registro Civil e Identificación (2020).
} 
del ámbito de aplicación de la determinación de maternidad por parto, las reglas de repudio y la renuncia de derechos en el caso en comento.

\section{Determinación y RECONOCIMIENTO DE MATERNIDAD en el Código CIVIL}

El artículo 183 de Código Civil manifiesta el principio romano de mater semper certa est de la siguiente manera:

"la maternidad queda determinada legalmente por el parto, cuando el nacimiento y las identidades del hijo y de la mujer que lo ha dado a luz constan en las partidas del Registro Civil",

en tanto reconoce en su inciso $2 .^{\circ}$ que, en otros casos, "la maternidad se determina por reconocimiento o sentencia firme en juicio de filiación, según lo disponen los artículos siguientes".

Así, nuestra legislación reconoce que, si bien son tres las posibles vías de determinación de la maternidad, existe un orden de prelación entre ellas, según el cual el parto será la primera y procede incluso sin el consentimiento de la madre biológica. En este sentido, la ley n. ${ }^{\circ} 4808$, del Registro Civil, indica en su artículo 31 que

"Las partidas de nacimiento deberán contener, además de las indicaciones comunes a toda inscripción, las siguientes: [...] $4 .^{\circ}$ Los nombres, apellidos, nacionalidad, profesión u oficio y domicilio de los padres, o los del padre o madre que le reconozca o haya reconocido. Se dejará constancia de los nombres y apellidos de la madre, aunque no haya reconocimiento, cuando la declaración del requirente coincida con el comprobante del médico que haya asistido al parto, en lo concerniente a las identidades del nacido y de la mujer que lo dio a luz"2.

De no aplicarse la regla precedente, podría determinarse la maternidad por la voluntad de la madre al efectuar el reconocimiento del hijo, y en el caso en que ello no ocurra, por sentencia judicial ${ }^{3}$. Así las cosas, el reconocimiento se manifiesta como un acto jurídico voluntario de la madre, mediante el cual determina su maternidad. En cambio, en el caso de ser fijada la filiación por sentencia judicial, la voluntad que consta es del hijo por sí, o representado, que desea establecer el vínculo filiativo. En razón de ello, podemos consignar que ambos esquemas difieren de la determinación del artículo 183 inciso $1^{\circ}$ del Código Civil, según el cual no es necesaria la voluntad de la madre, ni se observará una conducta del hijo por ser reconocido.

\footnotetext{
${ }^{2}$ Resaltado nuestro.

${ }^{3}$ En este sentido, Acuña San Martín (2016) y Corral Talciani (1999), p. 55.
} 
Esta conclusión es la que nos lleva a plantear la siguiente interrogante: ¿ existen fundamentos para otorgar la posibilidad de repudiar la determinación materna por parto, entendiendo, al igual que Gandulfo, que el "derecho a repudiación a favor del hijo, [es] de ejercicio discrecional para él"?4

\section{REPUDIACIÓN: FUNDAMENTO}

El punto de controversia en este caso es si es posible que un hijo, cuya filiación materna fue determinada por parto (por tanto, sin manifestación de voluntad de la madre ni la de él) ostente el derecho a repudiarla, aun cuando corresponda a la verdad biológica. ¿Es razonable prohibir la repudiación en este caso, pero aplicarla en los casos de reconocimiento? Claramente ello no supera el estándar ubi edem ratio ibi ius. Nuestro Código Civil permite, en virtud del artículo 191 y siguientes, que el hijo que no desee mantener una filiación determinada por reconocimiento pueda repudiarla, mas no lo autoriza de forma expresa cuando la filiación, como en este caso, sea determinada por parto. Por razones obvias, queda excluida del análisis la posibilidad de repudiar la determinación por sentencia judicial, pues, en palabras de Corral (las cuales compartimos) relativas al estudio de la ley n. $^{\circ} 19585$, refiere que

"[e]s obvio que sólo se puede repudiar el reconocimiento, y no así la determinación judicial de la filiación. Tampoco parece posible que pueda repudiarse el reconocimiento obtenido mediante la citación del supuesto padre o madre a confesar paternidad, puesto que como se hacía ver ya en la anterior regulación '¿Cómo podría repudiar el hijo un reconocimiento que él mismo ha provocado y perseguido?'. Se opondría a ello el principio de que nadie puede ir contra sus propios actos" ${ }^{5}$.

Habiendo despejado, entonces, las hipótesis de imposibilidad de repudio en el caso de determinación judicial de la filiación y admitido sea el caso de autorización legal expresa de permitir aquella reglada en el artículo 191 y siguientes del Código Civil, nos queda examinar el caso de la sentencia en comento. Para ello, nos detendremos en el análisis del fundamento de la repudiación: tensión entre la verdad biológica y la autonomía de la voluntad.

La determinación por parto supone, en la mayoría de los casos, que la mujer que da a luz es la madre biológica del hijo producto de aquél ${ }^{6}$, verificando así, que la filiación es manifestación del vínculo biológico de madre e hijo, según el artículo 183 inciso $1 .^{\circ}$ del Código Civil. El constatar que la verdad

${ }^{4}$ Gandulfo (2007), p. 203.

${ }^{5}$ Corral Talciani (1999), p. 61.

${ }^{6}$ No se cumpliría dicha premisa, por ejemplo, en los partos producto de embarazos por ovodonación. 
biológica es el fundamento de la filiación para nuestro ordenamiento también se expresa, de igual forma, en el artículo 195 del Código Civil, que consagra la libertad de investigación de la filiación, por los medios y formas indicadas en los artículos que le siguen. Así, es relevante destacar que el artículo 199 bis del mismo cuerpo normativo, señala que si la persona demandada no comparece a la audiencia preparatoria, o presenta dudas respecto de la filiación reclamada, se premune al juez para que ordene, de forma inmediata, la realización de una prueba pericial biológica a fin de establecer la filiación como resultado de una coincidencia genética.

De tal forma, tanto la determinación de maternidad por parto (artículo 183 del Código Civil) como las pruebas periciales biológicas reguladas en el artículo 199 y siguientes del Código constatan que la filiación debiese estar ligada a un vínculo biológico. En palabras de la Corte Suprema,

"la reforma introducida por la Ley $\mathrm{N}^{\circ} 19.585$ hace primar la verdad real o biológica por sobre la formal, por lo tanto, es presidido por el denominado principio de veracidad cuyo criterio rector es el derecho a la identidad"7.

Cabe hacer presente que, aunque existan casos de excepción en nuestra legislación, éstos no corresponden a la regla general del sistema ${ }^{8}$.

La repudiación a la filiación materna, así, aparece como un fenómeno de contrasentido. El parto es, por regla general, la manifestación inequívoca de coincidencia entre la verdad biológica y formal, protegida -como ya mencionamos- por el sistema filiativo instaurado por la ley n. ${ }^{\circ} 19585$. No obstante, el legislador entendió, ya en la tramitación de la ley, que ello podría ser modificado por voluntad del hijo. El primer informe de la Comisión de Constitución sobre la ley n..$^{\circ} 19585$ reconoció que suprimir eventualmente el repudio en casos de reconocimiento

"de nada servirá si el reconocimiento corresponde a la verdad biológica, porque así quedará acreditado en el proceso. Esta circunstancia es perfectamente lógica siguiendo el criterio que inspira al proyecto de ley de hacer prevalecer la verdad biológica, pero a la Comisión no le pareció equitativo imponerla a un hijo que no la desee" .

En este orden de ideas, es razonable que el hijo que ostente una filiación que no ha provocado y que no desee, pueda repudiar. El mantener una filiación

${ }^{7}$ G. R. E.E. con C. F. B. (2019), cons. 5.․ En similar sentido, C. M. P. con A. B. Hy otros (2020), cons. 3. ${ }^{\circ}$; J. P I. M. con L. S. G. (2016), cons. $6 .^{\circ}$; y F. T. C. con E. C. V. y otros (2015), cons. 3. ${ }^{\circ}$

${ }^{8}$ Nos referimos al reconocimiento de casos en que se determine la filiación cuando no exista correspondencia biológica. En este sentido, la posesión notoria -sea como prueba o acción (posibilidad a la cual ya nos hemos referido en otra ocasión, ver CONLEY GARRIDO [2020], pp. 229242)-, la adopción o la filiación determinada por técnicas de reproducción asistida.

${ }^{9}$ Biblioteca del Congreso Nacional (1998), pp. 29-30. 
biológica no deseada constituye, en los hechos, una carga que no es razonable soportar, aun cuando corresponda al vínculo biológico.

Y ello no es más que manifestación y ejercicio del principio de autonomía de la voluntad en casos de filiación. Gómez de la Torre identifica su aplicación como fundamento de la repudiación, señalando que "nadie puede ser obligado a adquirir derechos contra su voluntad, en este caso, a aceptar una filiación que no se quiere" 10 , y en la posibilidad de renunciar a los derechos conferidos por nuestro ordenamiento jurídico, al tenor del artículo 12 del Código de Bello, en tanto "miren al interés individual del renunciante, y que no esté prohibida su renuncia".

\section{REPUDIACIÓN Y ÁMBITO DE APLICACIÓN DE LOS ARTíCULOS 183 y 191 y Siguientes del Código CIVIL}

Para analizar la repudiación y su aplicación, nos remitiremos al caso en comento. A. B. P. L., en virtud de su autonomía de la voluntad, decidió renunciar a la filiación materna, determinada por parto, que corresponde a coincidencia genética. $\mathrm{Al}$ analizar esta abdicación, es cuando el fallo yerra. Para su análisis, procedemos a reproducir los considerandos pertinentes:

"SEXTO: Que, asentado lo anterior, la maternidad puede ser impugnada atacando alguno de los dos supuestos mencionados en el considerando anterior ${ }^{11}$. Ahora bien, lo razonado no obsta a que la maternidad pueda ser reconocida por otras vías, como por el reconocimiento que la madre hace del hijo o bien por sentencia firme dictada en juicio de filiación, hipótesis que no concurre en la especie, ya que tal como lo reconoce el recurrente, en su caso la maternidad quedó determinada al momento del parto.

SÉPTIMO: Que, cualquiera haya sido la vía para determinar la maternidad, siempre existirá la posibilidad de impugnarla a través de las acciones que establece nuestra legislación, pero es necesario antes, distinguir la forma en que previamente se ha establecido. Por lo tanto, en el caso de aquella determinada por el parto, la acción ha de estar orientada a acreditar que no hubo parto o que el hijo no fue producto de éste. En consecuencia, conforme a lo prescrito en el artículo 183 del Código Civil no resulta aplicable la acción de repudio contemplada en el artículo 191 del mismo cuerpo normativo, por cuanto la maternidad quedó determinada producto del documento médico que acreditó la existencia de un parto. Por el contrario, no ha existido una manifestación de voluntad de la madre con la finalidad de reconocer al recurrente como su hijo y que pueda ser repudiada por éste" 12 .

\footnotetext{
${ }^{10}$ Gómez de la Torre Vargas (2016), p. 166.

${ }^{11}$ Entiéndase que la "madre efectivamente haya parido y que el hijo que pasa por suyo sea producto del parto".
}

${ }^{12}$ A. B. P. L con Servicio de Registro Civil e Identificación (2020). 
De la redacción del fallo, nos podemos percatar que la Corte de Apelaciones de Antofagasta confundió, en su razonamiento, dos instituciones: la impugnación de la filiación y el repudio. La impugnación, como acción judicial, busca desvirtuar la filiación legalmente determinada. Así, en el caso de la impugnación de la maternidad, el artículo 217 del Código Civil señala que procederá ya sea "probándose falso parto, o suplantación del pretendido hijo al verdadero"; esto es, que en el caso en concreto no se cumplieron los requisitos del artículo 183, inciso $1 .^{\circ}$. En tanto, la repudiación no tiene como finalidad determinar si la filiación que se ostenta corresponde o no a un vínculo biológico, sino que es un acto de renuncia a derechos.

\section{Repudiación como manifestación del artículo 12 Código Civil}

El escueto artículo 191 del Código Civil, si bien no prohíbe de forma expresa la repudiación determinada por parto, sólo regula la repudiación del reconocimiento. ¿Significará ello que no puedan repudiarse los casos de filiación determinada por parto? Para una adecuada respuesta, debemos acudir a las reglas generales; esto es, al ya mencionado artículo 12 .

A. B. P. L., al repudiar, renuncia a un interés individual, que mira en su propio provecho o desventaja. No existiría colisión de un supuesto interés de la madre en mantener la filiación, pues la repudiación es un acto jurídico unilateral cuyo autor sólo puede ser el hijo. Así, solo resta esclarecer la aplicación de la última parte del artículo 12, que menciona que podrá renunciar a sus derechos (en este caso, el mantener una filiación materna determinada por parto) en tanto "no esté prohibida su renuncia". La autonomía de la voluntad o autonomía privada, en materia de familia, procede en tanto se establezcan los límites de su ejercicio, o en palabras de Barcia el

"ámbito de autonomía dentro de un estatuto regulatorio que es necesario fijar. Son las particularidades de este estatuto regulatorio las que señalan el contenido y límites de la autonomía privada” ${ }^{13}$.

Así, debemos esclarecer si existe alguna norma que señale algún límite a la repudiación, como manifestación de la autonomía de la voluntad reconocida en el artículo 12 del Código de Bello. Como ya analizamos, el artículo 191 del Código Civil no prohíbe la repudiación de la maternidad por parto. Es más, ni siquiera analiza dicha hipótesis, por lo cual fuerza es concluir que dicha norma no prohíbe la repudiación de la filiación materna determinada por parto. Es en definitiva el artículo 192 del Código Civil el que establece las prohibiciones a la renuncia a la filiación, esto es, los límites a la repudiación. La norma sólo indica que, en casos de aceptación expresa o tácita del reconocimiento, dicha

\footnotetext{
${ }^{13}$ Barcia Lehmann (2020).
} 
renuncia no procede, mas no de las filiaciones determinadas en otras hipótesis. De tal forma, en la regulación del Código Civil, el estatuto destinado a normar la repudiación, no prohíbe el ejercicio de la autonomía de la voluntad, como fundamento de renuncia a la filiación materna determinada por parto.

De tal forma, se cumplían en autos los requisitos establecidos por la ley para renunciar a la filiación, en atención a los artículos 12, 191 y 192 del Código Civil. Si bien es cierto que la autonomía de la voluntad en el derecho de familia se encuentra restringida, ello no significa que no sea aplicable a la repudiación de la filiación determinación por parto. En palabras de Lepín

"[e]n un escenario donde se garantiza el pleno ejercicio de los derechos humanos de los ciudadanos, incluso en el ámbito familiar, donde priman el pleno ejercicio de la libertad y la igualdad entre los integrantes del grupo familiar, son estos los primeros llamados a resolver sus conflictos" 14

y en este caso, al ejercer este acto de renuncia, A. B. P. L. se amparó en el ejercicio de su autonomía de la voluntad, la cual no está prohibida ni limitada respecto a esta hipótesis.

\section{Repudiación y derecho a la identidad}

La repudiación debe ser analizada a la luz de los derechos e intereses del hijo, pues es una institución que se basa en su sola voluntad. No es necesario que se funde la decisión o ésta merezca revisión judicial, y aun en casos en que no se discuta el vínculo biológico, basta la sola manifestación de voluntad del hijo en orden de repudiar la filiación, según las solemnidades ya señaladas.

Así, el principal derecho reflejado en la repudiación que ejerce el hijo es el de la identidad personal. Ésta se ha definido como "aquel que tiene toda persona sobre la verdad de su propia biografía" ${ }^{15}$. Corral lo conceptualiza como "la facultad de la persona de conocerse y darse a conocer tal como ella es" ${ }^{16}$. De tal forma, se hace patente que su contenido ya no puede ser entendido solo como la posibilidad de conocer los orígenes biológicos, sino tal como señala Latroph

"desde el punto de vista doctrinal abarca mucho más: en primer término, conocer los orígenes, no solo biológicos sino también familiares, étnicos, sociales y religiosos que identifican y definen a un individuo como tal; $y$, en segundo lugar, la posibilidad de exigir que dichas características sean respetadas en la proyección social de la persona"' ${ }^{17}$.

\footnotetext{
${ }^{14}$ Lepín (2014), p. 44.

${ }^{15}$ Allendes y Villavicencio (2013), p. 10.

${ }^{16}$ Corral Talciani (2018), p. 363 (destacado nuestro).

${ }^{17}$ Lathrop (2016).
} 
A su turno, el derecho a la identidad ha sido reconocido de forma expresa, como ocurre en el artículo $8^{\circ}$ de la Convención de Derechos del Niño, estableciéndose la obligación de los Estados a preservar su identidad. Así, se constata que este derecho está ligado a los vínculos familiares, y no distingue si ellos atienden a nexos biológicos o sociales. También se ha confirmado su injerencia en el sistema interamericano de Derechos Humanos de forma tácita, al entenderse integrado el ya mencionado artículo $8^{\circ}$ de la Convención de Derechos del Niño. De tal forma, la Corte Interamericana de Derechos Humanos reconoce que si bien no se menciona de forma expresa en la Convención al derecho a la identidad ${ }^{18}$, éste es "un elemento consustancial del ser humano" 19 , entendiendo por tal que "el conjunto de atributos y características que permiten la individualización de la persona en sociedad" ${ }^{20}$, esto es, sin fundar la identidad como equivalencia de un nexo biológico. Es por ello que, el hecho de repudiar la maternidad por parto, es sólo manifestación del ejercicio del derecho a la identidad, que el sujeto efectúa.

Mismo razonamiento lo comparte nuestro Tribunal Constitucional, fundando su argumentación en el artículo $5 .^{\circ}$ inciso $2 .^{\circ}$ de la Constitución Política de la República al indicar que

“[a]ún si se sostuviera que el reconocimiento del derecho a la identidad personal no encuentra sustento en los tratados internacionales ratificados por Chile y que se encuentran vigentes, como la Convención Americana de Derechos Humanos y el Pacto Internacional de Derechos Civiles y Políticos, porque no lo mencionan en forma expresa, igualmente habría que reconocer que el ejercicio de la soberanía, por parte del legislador, se encuentra limitado por el respeto a los derechos esenciales que emanan de la naturaleza humana, como es el caso del derecho a la identidad personal. [...] De esta forma puede sostenerse que el derecho a la identidad personal constituye un derecho implícitamente reconocido en nuestro ordenamiento constitucional, cuyo fundamento se encuentra en lo dispuesto en los artículos $1^{\circ}, 5^{\circ}$, inciso segundo, y $19 \mathrm{~N}^{\circ} 4^{\circ}$ de la Ley Fundamental, siendo un deber para los órganos del Estado respetarlo y promoverlo" ${ }^{21}$.

A mayor abundamiento, en nuestro Código Civil se menciona la libre investigación respecto de la filiación biológica el artículo 195 como parte de la identidad personal, pero ya mencionamos que ella no se agota en los vínculos cromosómicos. Es el propio artículo 201 el que decanta que, ante la disputa entre identidad biológica y social, se prefiera esta última. Corolario de lo anterior, es que somos partidarios de considerar que, el derecho a la identidad,

${ }^{18}$ G. vs. Uruguay (2011), párrafo 122.

${ }^{19}$ Steiner y Uribe (coords.) (2014), p. 109.

${ }^{20}$ Steiner y Uribe (coords.) (2014), p. 120.

${ }^{21}$ Requerimiento de inaplicabilidad por inconstitucionalidad presentado por L. A. K. L. sobre recurso de apelación, seguido ante la Corte Apelaciones de Santiago (2020), cons. 26. ${ }^{\circ}$. 
es exigible y que si bien pudo ser concebido como el derecho a conocer sus orígenes biológicos, también abarca el derecho a ser reconocido conforme a las características que permiten diferenciarnos respecto de otros, entre ellos, el respeto a la decisión de mantener o no una filiación determinada, permitiendo así, el ejercicio de renuncia de derechos del artículo 12 del Código Civil repudiando la maternidad determinada por parto.

De tal forma, la interpretación que debe efectuarse en estos casos, es pro personae y según las normativas ya analizadas. La lectura que debe efectuarse de los artículos 191 y 192 del Código Civil no debe ser restrictiva, sino entender que se reguló un caso específico de repudiación, lo que no prohíbe, por sí, el repudio de la maternidad determinada por parto. Concluir lo contrario, sería desconocer el ejercicio al derecho a la identidad y de la autonomía de la voluntad de personas mayores de edad, las cuales son aplicables al derecho de familia.

\section{Conclusiones}

El derecho a la filiación no puede ser entendido como el derecho a contar con una, sea biológica o no, sino como aquel que concierne a la propia identidad del sujeto. Los individuos nos convertirnos en más que sólo nuestra biología, por lo cual la interpretación que se debe efectuar de las reglas de la repudiación debe ser omnicomprensiva. Si bien el artículo 191 y siguientes del Código Civil mencionan su aplicación a propósito de filiaciones determinadas por reconocimiento, no es menos cierto que las reglas generales, esto es, el artículo 12, en ejercicio de la autonomía de la voluntad y el reconocimiento al derecho a la identidad, se debe aplicar en materia filiativa.

Así en este caso, A. B. P. L. no estaba impugnando la maternidad en los términos del artículo 217 del Código Civil, sino que renunciando a dicha filiación. No hay razón jurídica que justifique excluir del ámbito de aplicación del artículo 12 del Código Civil, en concordancia con el reconocimiento del derecho a la identidad, a la filiación determinada por parto, y así permitir el repudio.

\section{Bibliografía CitADA}

Acuña SAn Martín, Marcela (2016). "Cuarta parte Relaciones jurídicas entre los padres y el (la) hijo (a). Filiación. Título primero Aspectos generales sobre la filiación, determinación y acciones. Capítulo II Determinación de la filiación 1. Determinación de la maternidad, parto, reconocimiento de la madre, sentencia judicial”, en Jorge Del Picó Rubio (director). Derecho de familia. Santiago: Legal Publishing.

Allendes, Bárbara y Melanie Villavicencio (2013). "El hijo concebido mediante técnicas de reproducción humana asistida y su derecho a la identidad". Revista de Filosofía y Ciencias Jurídicas, n. ${ }^{\circ}$ 3, Valparaíso. 
Barcia Lehmann, Rodrigo (2020). Estructura del Derecho de Familia y de la Infancia. Santiago: Thomson Reuters, tomo I.

Conley Garrido, Bernardita (2020). "Notas sobre la naturaleza de la Posesión Notoria respecto de las acciones de filiación", en María Elisa Morales Ortiz y Pamela Mendoza Alonzo (dirs.). Estudios de Derecho Privado. II Jornadas Nacionales de Profesoras de Derecho Privado. Santiago: DER ediciones.

Corral Talciani, Hernán (1999). "Determinación de la filiación y acciones de estado en la reforma de la Ley $\mathrm{N}^{\circ} 19.585,1998$ ”. Revista de Derecho de la Universidad Católica de Valparaíso, n. ${ }^{\circ}$ 20, Valparaíso.

Corral Talciani, Hernán (2018). Curso de Derecho Civil. Parte General. Santiago: Thomson Reuters.

Gandulfo, Eduardo (2007). "Reconocimiento de paternidad: tópicos y cuestiones civiles". Revista Chilena de Derecho, vol. 34, n. ${ }^{\circ}$ 2, Santiago.

Gómez de la Torre Vargas, Maricruz (2017). El sistema filiativo. Filiación Biológica chileno. Valencia: Tirant lo Blanch.

LATHrop, Fabiola (2016). "Notas sobre una relectura del derecho a la identidad en contextos de filiación a la luz del desarrollo jurisprudencial chileno" en Cristián Lepín y Maricruz Gómez De la TorRe (coords.) Estudios de Derecho Familiar, I Jornadas Nacionales de Derecho Familiar, Santiago: Legal Publishing.

Lepín, Cristián (2014). "Los nuevos principios del Derecho de Familia". Revista Chilena de Derecho Privado, n. ${ }^{\circ}$ 23, Santiago.

Steiner, Christian y Patricia Uribe (coords.) (2014). Convención Americana sobre Derechos Humanos comentada. Disponible en: https://www.corteidh.or.cr/tablas/30237.pdf. [Fecha de consulta: 9 de junio de 2021].

\section{Otros documentos citados}

Biblioteca del Congreso Nacional (1988). Historia de la ley n. ${ }^{\circ} 19.585$. modifica el Código Civil y otros cuerpos legales en materia de filiación. Disponible en https://www.bcn.cl/historiadelaley/fileadmin/file_ley/6627/HLD_6627_6995 de31453451f4363b4436cf60da27.pdf [Fecha de consulta: 5 de mayo de 2021].

\section{Normas citadas}

\section{Código Civil.}

Ley n. ${ }^{\circ} 4808$, reforma la ley sobre el Registro Civil. Diario oficial de la República de Chile, Santiago, 10 de febrero de 1930.

Decreto n. ${ }^{\circ} 830$, que promulga Convención sobre los derechos del niño. Diario oficial de la República de Chile, Santiago, 27 de septiembre de 1990.

Ley n. ${ }^{\circ} 19585$, modifica el Código Civil y otros cuerpos legales en materia de filiación. Diario oficial de la República de Chile, Santiago, 26 de octubre de 1998. 


\section{Jurisprudencia citada}

G. vs. Uruguay (2011): Corte Interamericana de Derechos Humanos, sentencia de fondo y reparaciones, 24 de febrero de 2011, serie $\mathrm{C} \mathrm{n} .{ }^{\circ} 221$.

F. T. C. con E. C. V. y otros (2015): Corte Suprema, 25 de mayo de 2015, rol n. ${ }^{\circ}$ 1102-2015, Legal Publishing CL/JUR/4793/2015.

J. P. I. M. con L. S. G. (2016): Corte Suprema, 27 de julio de 2016, rol n. ${ }^{\circ} 38321-$ 2016, Legal Publishing CL/JUR/5321/2016.

A. B. P. L. con Servicio de Registro Civil e Identificación (2020): Corte de Apelaciones de Antofagasta, 03 de marzo de 2020, rol n. ${ }^{\circ}$ 571-2020, Legal Publishing CL/JUR/15626/2020.

G. R. E. E. con C. F. B. (2020): Corte Suprema, 16 de marzo de 2020, rol n. ${ }^{\circ}$ 11467-2019, Legal Publishing CL/JUR/20343/2020.

C. M. P. con A. B. H. y otros (2020): Corte Suprema, 13 de octubre de 2020, rol n. $30533-2020$, Legal Publishing CL/JUR/147979/2020.

Requerimiento de inaplicabilidad por inconstitucionalidad presentado por L. A. K. L. respecto de los artículos 206 del Código Civil; y $5^{\circ}$ transitorio, incisos tercero y cuarto, de la ley n. ${ }^{\circ} 19.585$, que modifica el Código Civil y otros cuerpos legales en materia de filiación, en el proceso rol n. ${ }^{\circ}$ 857-2020, sobre recurso de apelación, seguido ante la Corte Apelaciones de Santiago (2020): Tribunal Constitucional, 04 de agosto de 2021, rol n. ${ }^{\circ}$ 9961-2020.

SiglaS y ABREVIATURAS

cons. considerando

coords. coordinadores

dirs. directoras.

p. página

pp. páginas

vol. volumen 